\title{
Research on Police Professional Quality Training Methods of Police Academy Students
}

\author{
Lina Mu ${ }^{1}$ \\ ${ }^{1}$ Liaoning Police College, Dalian, Liaoning, 116036 \\ hunter2011@foxmail.com
}

Keywords: Police Academy Students, Police Professional Quality; Method

\begin{abstract}
Police takes the note of "serve the people wholeheartedly" for the purpose. Whether they can get the satisfaction of the people lies in whether the police have a highly qualified team. Improve the professional quality of the police, public security institutions focus on quality education. Police college students must improve the professional quality of the police as a systematic project, the paper combined with the current public security actual work of teaching and management institutions has explore ways to improve the professional quality of the police college students.
\end{abstract}

\section{Introduction}

Police can satisfaction of the people, the key lies in the construction of high-quality public security ranks. Police Colleges as a police contingent of the source and policemen training base, bear heavy responsibility for the public security contingent transfer of qualified personnel specialized police work. Thus, among the Police College Students in school four years learning life, we must pay attention to the cultivation of police professional quality for the future and lay a good foundation of quality from the police. Police Colleges must be professional quality of police work culture of students, as a systems engineering task, try to create a good environment for the growth of reserve police officers, public security institutions so that truly become the cradle of the People's Advocate.

\section{Situation Police College Students Police Career Awareness}

Professional Awareness of the Concept of Police. Career awareness police to police basis of the basic vocational knowledge to the police for professional values rational knowledge as the core, while police launched Reflections on career goals, career paths, professional ethics, professional ability, professional beliefs and career development of a range of issues, reflect individual police career awareness, understanding, emotion and attitude, cognitive and occupational integration of professional conduct. As can be seen from the concept, it is the police on the issue of occupational mental activity, self-consciousness is also reflected in police activity during the occupation.

Situation Police College Vocational Awareness. Students apply a variety of motives Police Colleges. Police College at the beginning of school, the police occupation of understanding is superficial, motivation to apply Police College also varied: some in order to obtain a stable job, some based on a police career idolatry, some For the police profession attractive, some swim, some are parents succumb to the pressure and so on. Whether motivated students how to apply for public security institutions, must give every student from the police occupation of the fantasy stage of development stage to consciously establish police career awareness, career awareness ultimately firmly establish police, entered a mature stage, which is the Police Colleges and the Police College must seriously think about.

Students suited to quasi-military management. At present the public security institutions have to follow military academies, the implementation of semi-militarized management system, which is the police management system. Such a system, if only to stay on the surface of the effort, always passive checks payable to lose the characteristics of public security management institutions, training police and strengthening of career awareness becomes empty. For the police academy 
students, from passive ideology must cope, into a proactive, consciously regulate his demeanor. Meanwhile, the police academy students must be established as soon as the police career awareness, consciously put all our energy into normal learning and training life.

Students awareness of the police profession exists errors. In the current teaching public security institutions, to cultivate police professionalism, generally throughout the daily lessons and various cultural activities on campus, basically, with indoctrination and guidance conducted. Career awareness policeman is necessary every police career awareness, career awareness if the police do not have, of course, can not become qualified people's police. It can be said that if the police career awareness is not strong, it is difficult to be a good cop. We say, consciously strengthen police career awareness training, career awareness continue to strengthen the police, every police career compulsory, therefore, for the Police College Students, in the daily life of learning and training, must focus on career awareness training, so as to lay a solid ideological foundation engaged in police work, which is very important.

\section{Police College Students' Quality Training Method}

Seek New Teaching Initiatives. Redefining the relationship between teaching and research, overcome the tendency of "heavy research, light teaching". Teaching and research universities are the two basic working university teachers. Over the years, public security institutions in the policy and management have been emphasizing the importance of education, but in practice, "the research, light teaching" it is an indisputable fact. Especially in teacher performance appraisal, job promotion, university appraisal hard power, when leadership performance evaluation, research is often regarded as the most important bargaining chip, too much emphasis on quantitative indicators of scientific research, so that the evaluation of the quality of teaching at the edge of the state. This "heavy research, light teaching" guide, a serious impact on teachers teaching seriously enthusiasm. Teaching and research are involved in the vital interests of teachers, management must be careful when formulating policy, starting from the height of the quality of teaching improved, to focus the guidance of teachers to teach well, good people up, to assess scientific research, you can set an appropriate threshold, so most teachers can achieve through their own efforts can, a good balance between teaching and research, and gradually form an aspect ratio in teaching, learning time, help, super situation.

Efforts to improve teaching quality, so that students learning anything, to apply their knowledge. First, to strengthen the training of new teachers, improve teaching level as soon as possible. In recent years, various public security institutions to meet the teaching requirements of universities, the introduction of a large number of highly educated young teachers, high degree, but they lack teaching experience, it may in the future teaching work will take a lot of detours, therefore, the need for given the necessary training of new teachers, and seriously carry out research activities. Especially for new teachers to teach Police Courses must ensure basic public security organs triennial testing exercise, expressly without testing exercise, can not directly teach the podium. For experienced teachers who will have to update their knowledge to solve problems. Second, pay attention to the process of teaching multimedia teaching methods and organic combination of traditional teaching methods. Multimedia is widely used, it has many advantages: rich in content, informative, clear writing, illustrations and so on it, if in the teaching process, coupled with the necessary animation, will bring great convenience classroom teaching, maximum limits to stimulate student interest in learning. Of course we can not ignore the traditional teaching methods. In short, modern teaching methods and traditional teaching methods combine the use of them, is the best teaching effect.

Strictly follow the training syllabus, to avoid formalism. Practical Teaching is an essential part of the construction of public security colleges, it is also a major step students' practical ability. Therefore, teachers need to be based on textbooks and public security practices, develop a reasonable training syllabus. Teaching process, the contents of the training must have training syllabus, effective deepen students 'understanding of the theory, improve their practical ability to strengthen the students' interest in learning. In this regard, not going through the motions, we should 
not formalized. In training teaching process, teachers should thoroughly among the students, the site FAQ. Specialized training teachers should pay close attention to their own professional development, develop and implement the most effective training teaching.

To Create A Good Atmosphere of Police Professional Quality Education. Clutching style construction does not relax. Current Atmosphere Police College is basically good, but there are many problems, no power on learning, lower test score requirements, exam engage in assault, minutes and so the presence of different levels of relations after the exam to find mention. Therefore, the management of public security institutions should attach great importance to carefully study, Mozhun crux, develop effective corrective measures. Students respect from their own, develop appropriate learning objectives, the initiative to carry out self-monitoring. In the study style construction process, should be through a series of measures to encourage students to recognize the importance of learning: Modern society has entered lifelong learning, social, intellectual updated to accelerate the speed of lifelong education, students must cherish the existing university life, to strengthen their own professional learning and ideological training, otherwise, enter the public security force, sooner or later will be eliminated by the society.

Teachers must serve as role models. University Students' outlook period is a critical period, life and values formation, despite the factors affecting their career development from all aspects, but as a teacher and student management is the most direct impact on the captain, the most timely, most weight. Teachers serve as role models must be done in order to enable students and teachers are willing to get close, I believe that the teacher, so the teacher as a friend, were ideologically deeper exchanges. Of course, school leaders at all levels must be a person of integrity, play an exemplary role, can really play its leadership role, thus forming a good ethos. Specifically, in student teaching and daily life management, leading cadres should take the lead in implementing the provisions, in accordance with regulations strictly according to law, not only can not carry out all kinds of unprincipled intervention intercede and work, but also the courage to uphold the principle of Teachers and student management cadres backing, so as to neutralize the unhealthy trends. In the daily teaching work, some students always put social habits into the school, paranoid that deal with everything you need to find and social relations in the final analysis the students rely on parents for the support of social relations, social relations can also say parents The higher the level, so undoubtedly interfere with normal school management is great. Therefore, the school leadership cadres have enough courage in handling difficult issues, the courage to play, withstood all kinds of pressure and unhealthy practices, in order to make students is college preparatory police officers after the police, the real from the heart do wholeheartedly serving the people, for the people justice.

Give Full Play to Both Positive and Negative Effects Typical of Education. To set a positive example, play a typical exemplary role. Typical sources of advanced a lot, we can choose a variety of social media channels acquire- advanced models as an educational material, but the effect from the point of view of education, poor. College students typically prefer on their side, they can be tangible. Therefore, in the process of establishing a positive example, choose to focus on typical industry from the police force, public security institutions also can tap their own culture and advanced management cadres, teachers and students of the three groups in the advanced models. Appraising the work of public security institutions every year in an orderly manner, but because of the tube, the limitations of the assessment system itself, lead to assessment results not convincing enough. Therefore, in the appraised work, we must adhere to the principle, in accordance with scientific standards, according to the real objective performance appraisal results, we selected a strong persuasive advanced models.

Make negative example of alert education. Typical negative effect vigilant education is an important quality of police training methods. Along with China's anti-corruption struggle deepening, also continue to show the typical negative, this is the best Police College Students conduct educational material alert. In the negative examples of choice, preferably the opposite of the police force or police typical college graduate from the police criminal typical individual, it would be in school by the special shock in the depths of the soul, more targeted, alert a greater role. Of course, the use of negative examples were vigilant education, we need to select the best time education. For 
example, you can choose the Police College Students participate in social practice before or after students return to school, to alert targeted education. Chose students to participate in social practice before this moment, because in the lack of social experience of college students, the ability to withstand risks and immunity is not strong, we must do prevent heart; be vigilant education student internships chose to return to school after the main reason During the internship students will encounter a lot of specific questions the public security institutions in the school learning process never met, must be correct guidance, to prevent the breeding of negative emotions. In short, no matter what method is the opposite of typical timing of alert conditions under which education, students must be taught the road from the police is not smooth, full of temptation and we must be vigilant, good anti-corrosion work.

\section{Conclusion}

In a word, to seek ways to improve the police professional quality education is a function of the great cause of future generations, we should follow the "Science and Education Police" strategic approach proposed by Ministry of Public Security, to follow the law of public security education, continue to explore ways to improve police college professional quality education.

\section{References}

[1] Zhang F. Police College Library in Police Training Achieve Professionalism. Yunnan Police Officer Academy, 2014.5.

[2] Liu Y. Career Development of Contemporary College Students' Literacy and Social Capabilities of Public Security Training Ways. Chengdu Textile College High Positive, 2015.4. 